\title{
NATIONAL RESEARCH AND EDUCATION NETWORK OF RUSSIA: DIRECTIONS OF DEVELOPMENT IN THE CONTEXT OF EXPANDING OF INTERNATIONAL COOPERATION
}

\author{
A.G. Abramov ${ }^{1, a}$, A.V. Evseev ${ }^{1}$, A.A. Gonchar ${ }^{2}$ \\ ${ }^{I}$ St. Petersburg branch of Joint Supercomputer Center of the Russian Academy of Sciences, nab. 14a \\ Smolenka river, Saint Petersburg, 199034, Russia \\ ${ }^{2}$ Joint Supercomputer Center of the Russian Academy of Sciences, 32 a Leninsky pr., Moscow, \\ 119334, Russia \\ E-mail: ${ }^{a}$ abramov@niks.su
}

The paper is devoted to certain aspects of the current functioning and development of National Research Computer Network (NIKS) in the status of National Research and Education Network (NREN) of Russia. The main emphasis is made on the discussion of foreign network connectivity of NIKS, the planned technological modernization and expansion of international cooperation with NRENs of the EAEU countries, the intensification of network and service interaction with leading European research and education consortia GÉANT and NORDUnet.

Keywords: national research computer network, NIKS, national research and education network, NREN, foreign network connectivity, international cooperation

Alexey Abramov, Anton Evseev, Andrey Gonchar

Copyright (C) 2021 for this paper by its authors. Use permitted under Creative Commons License Attribution 4.0 International (CC BY 4.0). 


\section{NIKS: current state and plans for development}

National Research Computer Network (NIKS, https://niks.su) [1, 2] was created in 2019 on the assignment of the Ministry of Science and Higher Education of the Russian Federation according to the results of integration of federal-level telecommunications networks in the fields of higher education (RUNNet) $[3,4]$ and science (RASNet).

In 2021, the Ministry approved a set of regulatory documents for NIKS - the management procedure and the concept and the roadmap for the functioning and development for 2021-2024. Works on the development of NIKS have been included in the National Project "Science and Universities" with the consolidation of activities, characteristics of the result and target indicators. NIKS has received the formal status of National Research and Education Network (NREN) of Russia; the functions of the administrator and the operator of the project are assigned to JSCC RAS.

Within the framework of the National Project it is planned the development of NIKS in the interests of research and education (R\&E) organizations of Russia, including with the aim of offering access to advanced scientific infrastructure of collective use (supercomputer centers, centers for collective use, unique scientific facilities, digital collections, data banks) by increasing the capacity of the network backbone, territorial accessibility and a set of services [1,2].

The indicators of the National Project determined that by the end of $202490 \%$ of the leading research organizations and higher education institutions (more than 300 organizations) from more than 50 regions and $100 \%$ of large supercomputer centers in the sphere of R\&E of the country will be connected to NIKS (in according to the selection criteria approved by the Ministry).

\section{Foreign connectivity and main directions of international cooperation}

Leading R\&E organizations of the country are systematically involved in the implementation of international research projects in priority scientific areas (including in the fields of high energy physics, astronomy, Earth observation, geophysics, climatology, etc.), that intensively use modern means of telecommunications, principles and technologies of distributed computing.

Some of the largest projects currently being implemented with the participation of Russian organizations include LHC, ITER, XFEL, FAIR, LIGO, Belle II, ESA, Copernicus, etc. Projects in their activities are guided by the principles of exchange and distribution of huge amounts of data in a trusted high-performance environment of the world NRENs. Operators of Russian Mega-Science class facilities (such as NRC "Kurchatov Institute" and JINR) use similar approaches in the implementation of telecommunications infrastructures.

Operators of global research projects, as a rule, impose restrictions on access to project resources and services through the networks of commercial service providers, grant access exclusively on the basis of high-performance NRENs infrastructures and maintaining uniform principles and standards of modern technological solutions $[3,5]$. In accordance with the rules and mechanisms approved at the level of world NRENs operators, the organization of global interconnection is implemented according to the "NREN to NREN" principle and excludes the possibility of passing traffic of any commercial telecommunications operators through their networks.

Support for international network interaction of target users is currently being implemented at NIKS on the basis of own high-speed telecommunications infrastructure in the direction of St. Petersburg - Helsinki - Stockholm - Amsterdam with a throughput of 10...100 Gbps and own backbone telecommunications nodes located in research centers abroad: CSC, IT Center for Science in Helsinki, NORDUnet in Stockholm, and NIKHEF in Amsterdam [fig. 1].

NIKS has a peering connection with the pan-European R\&E network consortium GÉANT [6] and direct interconnection with the R\&E network consortium of Nordic countries NORDUnet [7] (both $10 \mathrm{Gbps}$ ). 


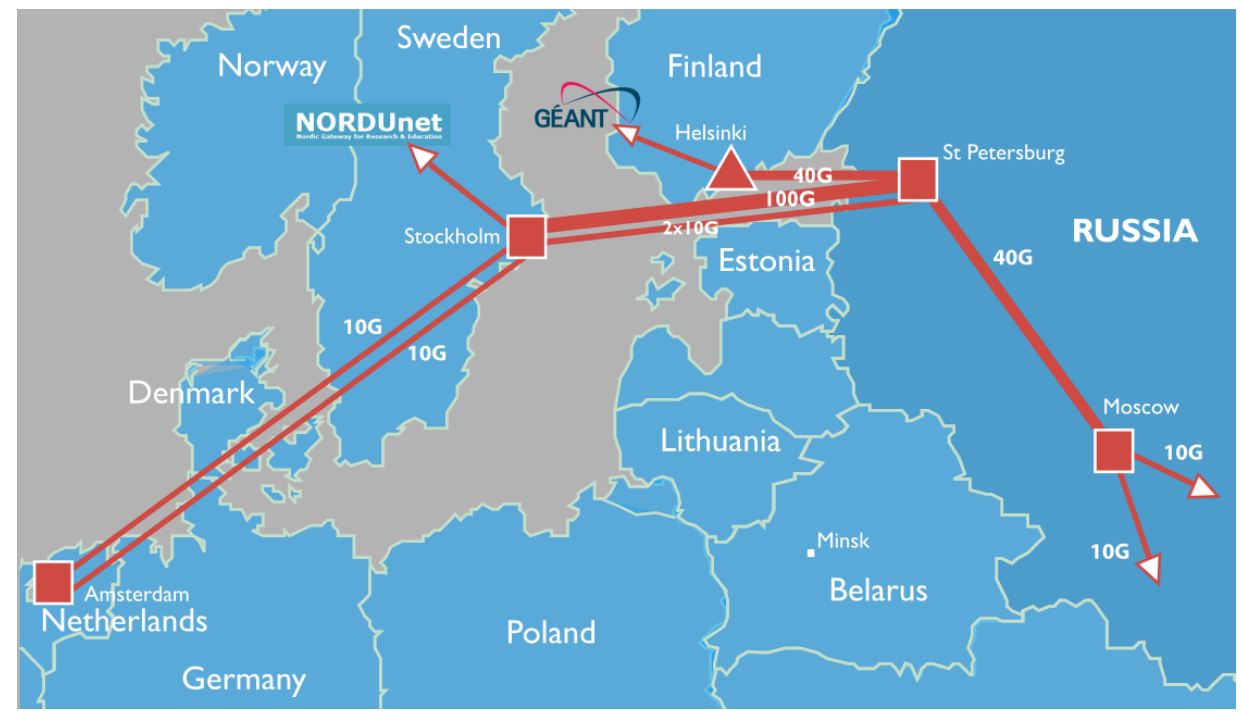

Figure 1. International network connectivity map of NIKS

The plans for the development of NIKS as a national infrastructure and service platform imply expanding cooperation with leading foreign NRENs and network consortia (including GÉANT, NORDUnet, TEIN3, RedCLARA, CERNET, etc.), increasing the level of involvement in promising international projects in the field of $R \& E$ and advanced digital technologies [fig. 2]. As examples, one can point to highly demanded service projects based on the principles of federated authentication eduGAIN (https://runnetaai.ru) and eduroam (https://eduroam.ru), in which NIKS participates as a national operator.

Specific activities for the development of NIKS in international directions involve extension of existing $100 \mathrm{Gbps}$ channel from Stockholm to Amsterdam, the creation of fault-tolerant ring network segments in Europe, the realization of direct interconnection with GÉANT with the expansion of capacity, including to provide users with access to the resources and services of NRENs outside Europe, full participation in global research projects, implemented using a network infrastructure with increased requirements for the quality of service.

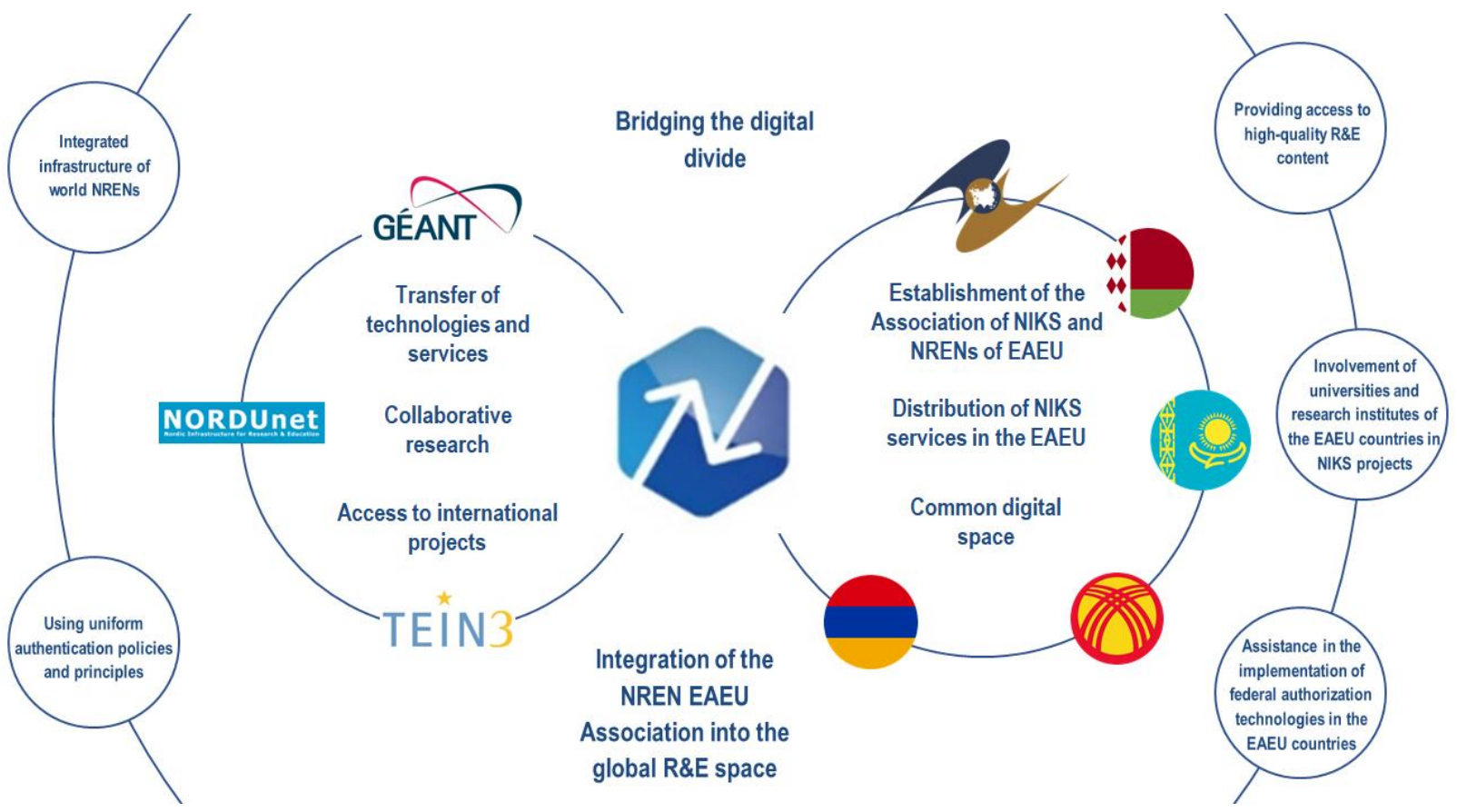

Figure 2. Scheme of key areas of international cooperation of NIKS 
In relation to other perspective areas, expansion of cooperation with research projects and R\&E networks of the Eurasian Economic Union (EAEU) countries and the study of opportunities to establish direct interconnections with NRENs of BRICS countries are being considered.

As part of the implementation of certain Strategic Directions for the Development of Eurasian Economic Integration until 2025, the creation of an association of NRENs of the EAEU member-states is under consideration and in progress. The goals of the association are the creation of a unified network infrastructure and service solutions for conducting scientific research, joint and coordinated interaction with world and regional sectoral networks, the introduction and expansion of the use of the system of federated authentication for effective interaction between scientists and researchers of the EAEU countries and for barrier-free access to R\&E services, as well as the development of recommendations and methodological documents on informatization of scientific activities and educational process.

To date, the drafts of the concept for the creation, maintenance and enhancement of the association of NRENs of the EAEU countries and the association agreement have developed and agreed upon, technological solutions for infrastructure are being worked out, taking into account the regulatory requirements of the countries, as well as the specifics of their licensing activities as telecommunications operators.

\section{Acknowledgement}

The publication was carried out within the framework of the state assignment of the SRISA RAS "Conducting fundamental scientific research (47 GP)" on topic no. FNEF-2021-0014 (05802021-0014, reg. no. 121031300097-1).

\section{References}

[1] Abramov A.G., Gonchar A.A., Evseev A.V., Shabanov B.M. The new generation National research computer network: current state and concept of development // Information technologies. 2021. V. 27(3). P. 115-124.

[2] Abramov A.G., Evseev A.V., Gonchar A.A., Telegin P.N., Shabanov B.M. National Research Computer Network of Russia: regulatory status and plans for the development of regional telecommunications infrastructure in 2021-2024 // CEUR Workshop Proceedings. 2021. V. 2930. P. 29-37.

[3] Abramov A.G., Evseev A.V. RUNNet: infrastructural and service basis of the national research and education network of the Russian Federation // In: Proc. VIII Int. Conf. "Distributed Computing and Grid-technologies in Science and Education" (GRID 2018). CEUR Workshop Proceedings. V. 2267. P. 52-57.

[4] Abramov A.G., Evseev A.V. Conceptual aspects of creating a new generation national research computer network in the Russian Federation // Information technologies. 2019. V. 25. P. 724-733. doi:10.17587/it.25.724-733

[5] Allocchio C., Balint L., Berkhout V., Bersee J., Izhvanov Y. et al. A History of international research networking: the people who made it happen. Wiley-VCH, 2010. 317 p.

[6] GÉANT: the official website. Available at: https://geant.org (accessed 30.09.2021)

[7] NORDUnet: the official website. Available at: https://nordu.net (accessed 30.09.2021) 